\section{International Myeloma Working Group updated criteria for the diagnosis of multiple myeloma}

\author{
SVincent Rajkumar, Meletios A Dimopoulos, Antonio Palumbo, Joan Blade, Giampaolo Merlini, María-Victoria Mateos, Shaji Kumar, Jens Hillengass, \\ Efstathios Kastritis, Paul Richardson, Ola Landgren, Bruno Paiva, Angela Dispenzieri, Brendan Weiss, Xavier LeLeu, Sonja Zweegman, Sagar Lonial, \\ Laura Rosinol, Elena Zamagni, Sundar Jagannath, Orhan Sezer, Sigurdur Y Kristinsson, Jo Caers, Saad Z Usmani, Juan José Lahuerta, Hans Erik Johnsen, \\ Meral Beksac, Michele Cavo, Hartmut Goldschmidt, Evangelos Terpos, Robert A Kyle, Kenneth C Anderson, Brian G M Durie, Jesus F San Miguel
}

This International Myeloma Working Group consensus updates the disease definition of multiple myeloma to include validated biomarkers in addition to existing requirements of attributable CRAB features (hypercalcaemia, renal failure, anaemia, and bone lesions). These changes are based on the identification of biomarkers associated with near inevitable development of CRAB features in patients who would otherwise be regarded as having smouldering multiple myeloma. A delay in application of the label of multiple myeloma and postponement of therapy could be detrimental to these patients. In addition to this change, we clarify and update the underlying laboratory and radiographic variables that fulfil the criteria for the presence of myeloma-defining CRAB features, and the histological and monoclonal protein requirements for the disease diagnosis. Finally, we provide specific metrics that new biomarkers should meet for inclusion in the disease definition. The International Myeloma Working Group recommends the implementation of these criteria in routine practice and in future clinical trials, and recommends that future studies analyse any differences in outcome that might occur as a result of the new disease definition.

\section{Introduction}

Multiple myeloma is a cytogenetically heterogeneous clonal plasma cell proliferative disorder ${ }^{1,2}$ and is almost always preceded by an asymptomatic premalignant stage termed monoclonal gammopathy of undetermined significance (MGUS). ${ }^{3,4}$ MGUS is present in roughly $3-4 \%$ of the population over the age of 50 years..$^{5-9}$ The diagnosis of MGUS requires the absence of hypercalcaemia, renal failure, anaemia, and bone lesions (referred to as CRAB features) that can be attributed to the underlying plasma cell disorder (all features must be absent; table 1). ${ }^{10-20}$ About $80 \%$ of multiple myeloma originates from non-IgM immunoglobulin MGUS (nonIgM MGUS), and 20\% from light-chain immunoglobulin MGUS (LC-MGUS). In the event of progression, IgM immunoglobulin MGUS (IgM MGUS) usually evolves into Waldenström macroglobulinaemia, but in rare instances IgM MGUS can progress to multiple myeloma (IgM myeloma). ${ }^{18,21-24}$ The rate of progression of MGUS to multiple myeloma is $0 \cdot 5-1 \%$ per year, but the precise risk is affected by the concentration of the monoclonal protein, type of monoclonal protein, serum free lightchain ratio, bone marrow plasmacytosis, proportion of phenotypically clonal plasma cells, and presence of immunoparesis. ${ }^{2429}$

Smouldering multiple myeloma is an intermediate clinical stage between MGUS and multiple myeloma in which the risk of progression to malignant disease in the first 5 years after diagnosis is much higher, at about 10\% per year. ${ }^{30}$ Prognostic models have been proposed to predict risk of progression, but lack concordance and need additional studies for verification. ${ }^{31}$ According to a population-based study from Scandinavia, smouldering multiple myeloma accounts for about $14 \%$ of all patients with multiple myeloma. ${ }^{32}$ As with MGUS, the diagnosis needs the absence of CRAB features attributable to the clonal plasma cell proliferative disorder, but the thresholds for monoclonal protein level and bonemarrow plasma cell (BMPC) percentage are different. Smouldering multiple myeloma is a biologically heterogeneous, clinically defined entity consisting of a subset of patients with biological premalignancy (ie, MGUS) and a subset with CRAB-negative malignancy (ie, multiple myeloma). ${ }^{33}$ It includes patients similar to those with MGUS, with a very low rate of progression, as well as patients who develop clinical symptoms and endorgan damage within the first 2 years of diagnosis. ${ }^{34,35}$ Unfortunately, no single pathological or molecular feature can be used to distinguish patients with smouldering multiple myeloma who have only clonal premalignant plasma cells from those with clonal malignant myeloma cells. A biomarker-based definition that accurately identifies the subset of patients with smouldering multiple myeloma and biological malignancy, who are at imminent risk of developing CRAB features (and should therefore be considered for therapy), is needed. ${ }^{34}$

\section{Rationale for updating of diagnostic criteria}

The present disease definitions of smouldering multiple myeloma and multiple myeloma were reported by the International Myeloma Working Group (IMWG) in been used in clinical practice as well as in research studies and trials in the past decade. ${ }^{36,37}$ One of the major difficulties in multiple myeloma is that, unlike other malignancies, the disease definition is clinicopathological; it needs overt clinical manifestations of serious endorgan damage, such as osteolytic bone lesions and renal failure, before the diagnosis can be made. This conundrum has ensured that patients cannot get early therapy to prevent organ damage, and has prevented any 2003. ${ }^{10}$ With minor clarifications, ${ }^{11}$ these criteria have

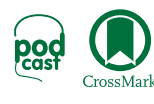

Lancet Oncol 2014; 15: e538-48 See Online for a podcast interview with S Vincent Rajkumar Division of Hematology, Mayo Clinic, Rochester, MN, USA (Prof S V Rajkumar MD Prof S Kumar MD, Prof A Dispenzieri MD, Prof R A Kyle MD); Department of Clinical Therapeutics, University of Athens, School of Medicine, Athens, Greece (Prof M A Dimopoulos MD, E Kastritis MD, ETerpos MD); Myeloma Unit, Division of Hematology, University of Torino, Azienda OspedalieroUniversitaria Città della Salute e della Scienza di Torino, Torino, Italy

(Prof A Palumbo MD); Hospital Clinic, Barcelona, Spain (J Blade MD, L Rosinol MD); Amyloidosis Center, University Hospital Policlinico San Matteo, Pavia, Italy (Prof G Merlini MD); University Hospital of Salamanca/IBSAL, Salamanca, Spain (M V Mateos MD); Department of Hematology, Oncology and Rheumatology, University of Heidelberg, Heidelberg, Germany (J Hillengass MD Prof H Goldschmidt MD); DanaFarber Cancer Institute, Boston, MA, USA (Prof P Richardson MD, Prof K ( Anderson MD); Memorial Sloan Kettering Cancer Center, New York, NY, USA (O Landgren MD); Clinica Universidad de Navarra, Centro de Investigacion Medica Aplicada (CIMA), Pamplona Spain (B Paiva MD, Prof J F San Miguel MD); Abramson Cancer Center, University of Pennsylvania, Philadelphia, PA, USA (B Weiss MD); University Hospital of Lille, Lille, France (X Leleu MD); Department of Hematology, VU University Medical Center, Amsterdam, Netherlands (Prof S Zweegman MD); Department of Hematology 


\begin{tabular}{|c|c|c|c|}
\hline & Definition $^{\dagger+}$ & Progression rate & Primary progression events \\
\hline $\begin{array}{l}\text { Non-IgM monoclonal } \\
\text { gammopathy of } \\
\text { undetermined significance }^{10}\end{array}$ & $\begin{array}{l}\text { Serum monoclonal protein (non-lgM type) }<30 \mathrm{~g} / \mathrm{L} \\
\text { Clonal bone marrow plasma cells }<10 \% * \\
\text { Absence of end-organ damage such as hypercalcaemia, renal insufficiency, anaemia, and bone lesions } \\
\text { (CRAB) or amyloidosis that can be attributed to the plasma cell proliferative disorder }\end{array}$ & $1 \%$ peryear & $\begin{array}{l}\text { Multiple myeloma, solitary } \\
\text { plasmacytoma, immunoglobulin- } \\
\text { related amyloidosis (AL, AHL, AH) }\end{array}$ \\
\hline $\begin{array}{l}\text { IgM monoclonal } \\
\text { gammopathy of } \\
\text { undetermined significance }^{11}\end{array}$ & $\begin{array}{l}\text { Serum IgM monoclonal protein }<30 \mathrm{~g} / \mathrm{L} \\
\text { Bone marrow lymphoplasmacytic infiltration }<10 \% \\
\text { No evidence of anaemia, constitutional symptoms, hyperviscosity, lymphadenopathy, } \\
\text { hepatosplenomegaly, or other end-organ damage that can be attributed to the underlying } \\
\text { lymphoproliferative disorder }\end{array}$ & $1.5 \%$ per year & $\begin{array}{l}\text { Waldenström } \\
\text { macroglobulinaemia, } \\
\text { immunoglobulin-related } \\
\text { amyloidosis (AL, AHL, AH) }\end{array}$ \\
\hline $\begin{array}{l}\text { Light-chain monoclonal } \\
\text { gammopathy of } \\
\text { undetermined } \\
\text { significance }{ }^{8,12}\end{array}$ & $\begin{array}{l}\text { Abnormal FLC ratio }(<0.26 \text { or }>1.65 \text { ) } \\
\text { Increased level of the appropriate involved light chain (increased } \mathrm{kLLC} \text { in patients with ratio }>1.65 \text { and } \\
\text { increased } \lambda \mathrm{FLC} \text { in patients with ratio }<0.26 \text { ) } \\
\text { No immunoglobulin heavy chain expression on immunofixation } \\
\text { Absence of end-organ damage such as hypercalcaemia, renal insufficiency, anaemia, and bone lesions } \\
\text { (CRAB) or amyloidosis that can be attributed to the plasma cell proliferative disorder } \\
\text { Clonal bone marrow plasma cells }<10 \% \\
\text { Urinary monoclonal protein }<500 \mathrm{mg} / 24 \mathrm{~h}\end{array}$ & $0.3 \%$ peryear & $\begin{array}{l}\text { Light chain multiple myeloma, } \\
\text { immunoglobulin light-chain } \\
\text { amyloidosis }\end{array}$ \\
\hline Solitary plasmacytoma ${ }^{13-16}$ & $\begin{array}{l}\text { Biopsy-proven solitary lesion of bone or soft tissue with evidence of clonal plasma cells } \\
\text { Normal bone marrow with no evidence of clonal plasma cells } \\
\text { Normal skeletal survey and MRI (or CT) of spine and pelvis (except for the primary solitary lesion) } \\
\text { Absence of end-organ damage such as hypercalcaemia, renal insufficiency, anaemia, or bone lesions } \\
\text { (CRAB) that can be attributed to a lymphoplasma cell proliferative disorder }\end{array}$ & $\begin{array}{l}\text { About } 10 \% \text { within } \\
3 \text { years }\end{array}$ & Multiple myeloma \\
\hline $\begin{array}{l}\text { Solitary plasmacytoma } \\
\text { with minimal marrow } \\
\text { involvement } \dagger^{13-16}\end{array}$ & $\begin{array}{l}\text { Biopsy-proven solitary lesion of bone or soft tissue with evidence of clonal plasma cells } \\
\text { Clonal bone marrow plasma cells }<10 \% \\
\text { Normal skeletal survey and MRI (or CT) of spine and pelvis (except for the primary solitary lesion) } \\
\text { Absence of end-organ damage such as hypercalcaemia, renal insufficiency, anaemia, or bone lesions } \\
\text { (CRAB) that can be attributed to a lymphoplasma cell proliferative disorder }\end{array}$ & $\begin{array}{l}60 \% \text { (bone) or } 20 \% \\
\text { (soft tissue) within } \\
3 \text { years }\end{array}$ & Multiple myeloma \\
\hline POEMS syndrome $\ddagger^{11,17}$ & $\begin{array}{l}\text { Polyneuropathy } \\
\text { Monoclonal plasma cell proliferative disorder (almost always } \lambda \text { ) } \\
\text { Any one of the following three other major criteria: } \\
\text { Sclerotic bone lesions } \\
\text { Castleman's disease } \\
\text { Elevated levels of VEGFAS } \\
\text { Any one of the following six minor criteria: } \\
\text { Organomegaly (splenomegaly, hepatomegaly, or lymphadenopathy) } \\
\text { Extravascular volume overload (oedema, pleural effusion, or ascites) } \\
\text { Endocrinopathy (adrenal, thyroid, pituitary, gonadal, parathyroid, pancreatic) } \\
\text { Skin changes (hyperpigmentation, hypertrichosis, glomeruloid haemangiomata, plethora, } \\
\text { acrocyanosis, flushing, white nails) } \\
\text { Papilloedema } \\
\text { Thrombocytosis/polycythaemia }\end{array}$ & NA & NA \\
\hline 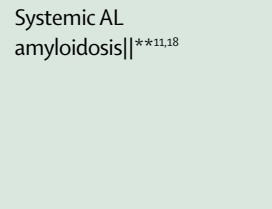 & $\begin{array}{l}\text { Presence of an amyloid-related systemic syndrome (eg, renal, liver, heart, gastrointestinal tract, or } \\
\text { peripheral nerve involvement) } \\
\text { Positive amyloid staining by Congo red in any tissue (eg, fat aspirate, bone marrow, or organ biopsy) } \\
\text { Evidence that amyloid is light-chain-related established by direct examination of the amyloid using mass } \\
\text { spectrometry-based proteomic analysis, or immunoelectronmicroscopy, and } \\
\text { Evidence of a monoclonal plasma cell proliferative disorder (serum or urine monoclonal protein, } \\
\text { abnormal free light-chain ratio, or clonal plasma cells in the bone marrow) }\end{array}$ & NA & $\begin{array}{l}\text { Some patients might develop } \\
\text { multiple myeloma }\end{array}$ \\
\hline \multicolumn{4}{|c|}{ 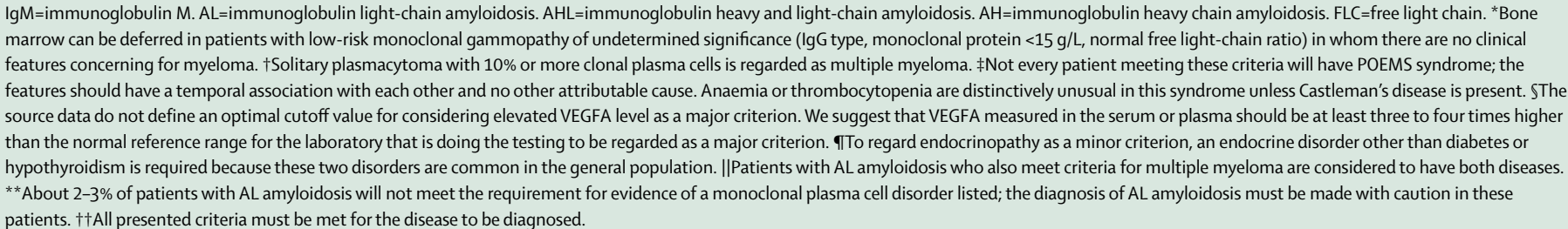 } \\
\hline
\end{tabular}

and Medical Oncology, Winship Cancer Institute, Emory University, Atlanta, GA, USA (Prof S Lonial MD); Seràgnoli Institute of Hematology, Bologna University School of Medicine, Bologna, Italy attempts at cancer treatment at a stage when it is in its most susceptible microenvironment-dependent state. These criteria were acceptable in an era of restricted treatment options that had substantial toxic effects and did not show any apparent clinical benefit from early intervention. However, this definition can no longer be justified because treatment options have greatly improved, and data show early intervention in high-risk asymptomatic patients can extend survival. ${ }^{38}$ Moreover, advances in laboratory and imaging techniques call for an update on the specific variables that should be regarded as meeting the criteria for CRAB features. ${ }^{39}$ 
Finally, some revisions to the monoclonal protein and bone marrow plasma cell requirements are also needed.

\section{Myeloma-defining biomarkers}

To intervene before the development of end-organ damage in multiple myeloma, biomarkers are needed that accurately identify the subset of patients with smouldering multiple myeloma who have biological malignancy and are at imminent risk of progression..$^{35,40-44}$ A Mayo Clinic study ${ }^{45}$ of patients with smouldering multiple myeloma reported that having a BMPC of at least $60 \%$ can be used as a marker to identify patients with a notably high risk (about 90\%) of progression within 2 years of diagnosis. In 2011 at a summit in London, UK, the IMWG reached a consensus that, if reliable biomarkers associated with roughly an $80 \%$ probability of progression to multiple myeloma within 2 years were identified, such patients should be regarded as having multiple myeloma and offered therapy. This threshold would identify a small cohort of smouldering multiple myeloma with a median time to development of end-organ damage of about 12 months, for whom a delay of therapy would be unreasonable. The IMWG consensus was driven by the following considerations. First, this very high-risk cohort is not representative of most patients with smouldering multiple myeloma, in view of the $40 \%$ per year risk of progression (based on the prespecified definition), compared with the $10 \%$ per year risk of progression with smouldering multiple myeloma. Second, one of the reasons to delay therapy in smouldering multiple myeloma is based on the fact that a substantial proportion of patients can remain free of progression for long periods of time. For example, 50\% of patients with smouldering multiple myeloma do not progress in the first 5 years, and roughly $30 \%$ are free of progression after 10 years. ${ }^{30}$ Such considerations do not apply to this ultra-high risk subgroup in which few, if any, patients are free of progression beyond 3 years. Third, the proportion of patients who do not progress within 2 years (up to $20 \%$ ) was regarded to be reasonable, because these patients are probably not very different from some patients with multiple myeloma who have minimal CRAB features for whom prompt treatment is widely accepted (eg, patients with one or two lytic lesions, or mild anaemia), yet who can remain stable without therapy. Fourth, the results of end-organ damage, especially acute renal failure or pathological fracture, were judged to be unacceptably severe, with risk of substantial long-term morbidity. Therefore, we believed that persisting with a disease definition that demanded such damage occur before the disease is called multiple myeloma was unreasonable for patients. Finally, we believed that major advances have been made in the treatment of multiple myeloma, and although watchful waiting was appropriate in an era of only alkylating agents and corticosteroids, it was not justifiable for ultrahigh-risk patients in view of the availability of several safer and more effective treatments. ${ }^{46-51}$ Trials with alkylators that did not show an increase in overall survival with early treatment for smouldering multiple myeloma were underpowered, and did not focus on high-risk patients..$^{52,53}$ A randomised trial ${ }^{18}$ done in 2013 reported that early therapy for smouldering multiple myeloma can extend overall survival, greatly diminishing concerns that treatment of patients with a very high-risk of smouldering multiple myeloma as multiple myeloma will lead to overtreatment or unnecessary therapy.

\section{Revisions to laboratory and imaging criteria for $C R A B$}

In addition to the previous discussion on incorporation of additional biomarker-defined myeloma-defining events to the standard CRAB features, updates are also needed that take into account the substantial changes to laboratory testing and imaging used in the diagnosis of multiple myeloma that have happened since the initial publication of the IMWG diagnostic criteria. These include better methods of detecting bone and extramedullary disease using CT (including low-dose whole body CT), MRI, 18F-fluorodeoxyglucose (FDG) PET, and FDG-PET with CT (PET-CT). ${ }^{5456}$ They also include better estimation of renal damage by use of creatinine clearance in addition to serum creatinine measurements, and the criteria for clonal bone marrow plasma cells needed on bone marrow examination have been revised.

\section{Other revisions}

Other minor clarifications to the disease definition are needed to account for patients with non-secretory multiple myeloma (where there is no monoclonal protein in any tests), and patients with normal or scarcely involved $(<10 \%$ clonal plasma cells) bone marrow examinations who have multiple lytic lesions, plasmacytomas (bony or extramedullary), or other CRAB features without diffuse infiltration of the marrow.

\section{Revised IMWG criteria for diagnosis of myeloma} The updated IMWG criteria for diagnosis of multiple myeloma are given in the panel; the supporting data for each of the changes are discussed below. The term multiple myeloma refers to multiple myeloma requiring therapy.

\section{Bone marrow plasma cells of $60 \%$ or greater}

In 2011, a re-analysis of the original Mayo Clinic cohort of smouldering multiple myeloma noted that only six (2\%) of 276 patients had a BMPC of $60 \%$ or greater (defined as the highest percentage noted on an aspirate or trephine biopsy sections). The median progression-free survival was 7.7 months (95\% CI $0.4-14.9)$, and five of the six patients $(83 \%)$ patients had progressed or died by 14 months. ${ }^{45}$

To validate this finding, a study was done in a new group of 651 patients with smouldering multiple
(E Zamagni MD,

Prof M (avo MD); Mount Sina Cancer Institute, New York, NY, USA (Prof S Jagannath MD); Memorial Hospital, Istanbul, Turkey (Prof O Sezer MD); Karolinska University Hospital, Karolinska Institutet, Stockholm, Sweden (SY Kristinsson MD); Department of Hematology, CHU de Liege, Liege, Belgium (J Caers MD); Levine Cancer Institute, Carolinas HealthCar System, Charlotte, NC, USA (S Z Usmani MD); Servicio de Hematología, Hospital Universitario 12 de Octubre, Madrid, Spain (J L Lahuerta MD); Department of Haematology, Aalborg University Hospital, Aalborg, Denmark (Prof HE Johnsen MD); Ankara University School of Medicine Ankara, Turkey (Prof M Beksac MD); and CedarsSinai Comprehensive Cance Center, Los Angeles, CA, USA (Prof B G M Durie MD)

Correspondence to: Prof S Vincent Rajkumar, Division of Hematology, Mayo Clinic, 200 First St SW, Rochester MN 55905, USA rajkumar.vincent@mayo.edu 
Panel: Revised International Myeloma Working Group diagnostic criteria for multiple myeloma and smouldering multiple myeloma

\section{Definition of multiple myeloma}

Clonal bone marrow plasma cells $\geq 10 \%$ or biopsy-proven bony or extramedullary plasmacytoma* and any one or more of the following myeloma defining events:

- Myeloma defining events:

- Evidence of end organ damage that can be attributed to the underlying plasma cell proliferative disorder, specifically:

- Hypercalcaemia: serum calcium $>0.25 \mathrm{mmol} / \mathrm{L}$ ( $>1 \mathrm{mg} / \mathrm{dL}$ ) higher than the upper limit of normal or $>2.75 \mathrm{mmol} / \mathrm{L}(>11 \mathrm{mg} / \mathrm{dL})$

- Renal insufficiency: creatinine clearance $<40 \mathrm{~mL}$ per mint or serum creatinine $>177 \mu \mathrm{mol} / \mathrm{L}$ ( $>2 \mathrm{mg} / \mathrm{dL})$

- Anaemia: haemoglobin value of $>20 \mathrm{~g} / \mathrm{L}$ below the lower limit of normal, or a haemoglobin value $<100 \mathrm{~g} / \mathrm{L}$

- Bone lesions: one or more osteolytic lesions on skeletal radiography, $\mathrm{CT}$, or PET-CT $\ddagger$

- Any one or more of the following biomarkers of malignancy:

- Clonal bone marrow plasma cell percentage* $\geq 60 \%$

- Involved:uninvolved serum free light chain ratio $\$ \geq 100$

- $>1$ focal lesions on MRI studies $\Phi$

\section{Definition of smouldering multiple myeloma}

Both criteria must be met:

- Serum monoclonal protein ( $\operatorname{lgG}$ or $\lg \mathrm{A}$ ) $\geq 30 \mathrm{~g} / \mathrm{L}$ or urinary monoclonal protein $\geq 500 \mathrm{mg}$ per $24 \mathrm{~h}$ and/or clonal bone marrow plasma cells $10-60 \%$

- Absence of myeloma defining events or amyloidosis

$\mathrm{PET}-\mathrm{CT}={ }^{18} \mathrm{~F}$-fluorodeoxyglucose PET with $\mathrm{CT}$. ${ }^{*}$ Clonality should be established by showing $\mathrm{k} / \lambda$-light-chain restriction on flow cytometry, immunohistochemistry, or immunofluorescence. Bone marrow plasma cell percentage should preferably be estimated from a core biopsy specimen; in case of a disparity between the aspirate and core biopsy, the highest value should be used. $\uparrow$ Measured or estimated by validated equations. łIf bone marrow has less than $10 \%$ clonal plasma cells, more than one bone lesion is required to distinguish from solitary plasmacytoma with minimal marrow involvement. SThese values are based on the serum Freelite assay (The Binding Site Group, Birmingham, UK). The involved free light chain must be $\geq 100 \mathrm{mg} / \mathrm{L}$. IEach focal lesion must be $5 \mathrm{~mm}$ or more in size.
(5\%) of 121 patients with smouldering multiple myeloma in a third study were reported to have BMPC $60 \%$ or greater, and all progressed to multiple myeloma within 2 years. ${ }^{58}$

BMPC estimation for diagnosis is based on either conventional bone marrow aspirate or biopsy examination. BMPC estimation should not be based on the proportion of plasma cells reported by flow cytometry; studies are ongoing to determine whether flow-based enumeration is feasible..$^{59}$ If a discrepancy exists between BMPC estimation in the biopsy sample and aspirate, the higher of the two values should be used. ${ }^{60}$

\section{Serum free light chain ratio of 100 or greater}

The free light chain (FLC) assay is an automated nephelometric assay that identifies and measures $\kappa$ and $\lambda$ light immunoglobulin chains that circulate unbound to heavy chains in the serum. ${ }^{61-63}$ The normal ratio for FLC$\kappa / \lambda$ is $0 \cdot 26-1 \cdot 65$. In clonal plasma cell disorders, excess production of one FLC type (the clonal component referred to as the involved light chain) often results in an abnormal FLC ratio. ${ }^{64}$ About a third of patients with MGUS, $70 \%$ of patients with smouldering multiple myeloma, and more than $90 \%$ of patients with multiple myeloma have altered FLC ratios that indicate excess production of a clonal FLC by the proliferating plasma cell population. . $^{27,44,65,66}$ The presence of an abnormal FLC ratio, and the extent to which the FLC ratio is abnormal, predict risk of progression in MGUS, smouldering multiple myeloma, amyloid light-chain (AL) amyloidosis, and solitary plasmacytoma. . $7,44,67^{-1}$

Dispenzieri and colleagues ${ }^{44}$ reported that in patients with smouldering multiple myeloma, an involved to uninvolved FLC ratio of 8 or more is associated with about a $40 \%$ risk of progression within the first 2 years from diagnosis. Subsequently, Larsen and colleagues ${ }^{68}$ studied 586 patients with smouldering multiple myeloma to determine the threshold at which the FLC ratio is associated with an $80 \%$ probability of progression to multiple myeloma or related malignant disease within 2 years. A serum involved to uninvolved FLC ratio of at least 100 was noted in 90 (15\%) patients of the total cohort; the involved FLC level was higher than the normal range in all. The risk of progression to multiple myeloma within the first 2 years in patients with an FLC ratio of at least 100 was $72 \%$; the risk of progression to multiple myeloma or AL amyloidosis in 2 years was $79 \%$. The risk of progression to multiple myeloma or $\mathrm{AL}$ amyloidosis for patients with an FLC ratio of at least 100 and an involved FLC level at least $1000 \mathrm{mg} / \mathrm{L}$ was $82 \%$ at 2 years, and $93 \%$ at 3 years. Taking an absolute FLC level threshold into account improved positive predictive value of the FLC assay, but lowered sensitivity. Importantly, $27 \%$ of patients with a FLC ratio of at least 100 had acute renal failure as the myeloma-defining event. The researchers concluded that a FLC ratio of at least 100 is a predictor of imminent progression in smouldering 
multiple myeloma, and that such patients should be regarded as having multiple myeloma requiring therapy.

Similar results were obtained in work by Kastritis and colleagues $^{57}$ from the Greek Myeloma Group. In their investigation of 96 patients with smouldering multiple myeloma, seven $(7 \%)$ had an involved to uninvolved FLC ratio of at least 100 , and almost all progressed within 18 months (HR 9.0 [95\% CI 2.15-39.00], $\mathrm{p}=0.003)$. In a third study, ${ }^{58}$ the risk of patients with smouldering multiple myeloma with an involved to uninvolved FLC ratio of at least 100 progressing within 2 years was $64 \%$. Although these studies did not need a minimum involved FLC level, to reduce possibility of error the new criteria require a minimum involved FLC level of at least $100 \mathrm{mg} / \mathrm{L}$.

\section{MRI with more than one focal lesion}

MRI is beneficial in evaluating patients with smouldering multiple myeloma, and is recommended as part of the initial assessment. ${ }^{54}$ Abnormal MRI imaging features in smouldering multiple myeloma include both focal lesions (involving bone or bone marrow), and diffuse bone marrow abnormalities. These abnormalities have been associated with increased risk of progression in smouldering multiple myeloma ${ }^{69-71}$ However, only within the past 5 years have investigators precisely determined the level of abnormality that is associated with a high probability of progression within 2 years. Hillengass and colleagues $^{72}$ studied 149 patients with smouldering multiple myeloma with whole-body MRI. Focal lesions were detected in $42(28 \%)$ patients; more than one focal lesion was identified in $23(15 \%)$ patients of the total cohort. The presence of more than one focal lesion was associated with a substantial increase in risk of progression (HR 4.05, p<0 001; univariate analysis). The median time to progression was 13 months, and $70 \%$ of patients had progressed at 2 years. On multivariate analysis, presence of more than one focal lesion remained a significant predictor of progression. In patients with more than one focal lesion on MRI, if such lesions are small $(<5 \mathrm{~mm})$ or equivocal, additional imaging with CT or PET-CT should be considered before making the diagnosis of multiple myeloma.

Kastritis and colleagues ${ }^{73}$ analysed data from the Greek Myeloma Database and identified 65 patients with smouldering multiple myeloma who underwent spinal MRI and were followed up for a minimum of $2 \cdot 5$ years. In this cohort, nine (14\%) patients had more than one focal lesion. The median time to progression to multiple myeloma for patients with more than one focal lesion was 15 months (95\% CI 6-26). At 2 years, 69\% of patients had progressed, as had $85 \%$ at 3 years. By contrast, the median time to progression for patients with one or no focal lesions was over 5 years $(\mathrm{p}<0 \cdot 001)$.

A diffuse marrow infiltration pattern is associated with an increased risk of progression, but is not recommended as adequate to establish the diagnosis of multiple myeloma. Additional data are needed on the specific risk of progression in the first 2 years in the absence of focal lesions and extreme bone marrow plasmacytosis. ${ }^{74,75}$ In the study by Hillengass, ${ }^{72}$ diffuse MRI infiltration was associated with a HR of $3 \cdot 5(\mathrm{p}<0 \cdot 001)$. A 2014 analysis $^{76}$ shows that the increase in number or size of focal lesions in follow-up MRI of patients with smouldering multiple myeloma has additional predictive value, including information on growth dynamics of the plasma cell tumours in bone marrow. Therefore, in patients with diffuse infiltration, solitary focal lesion, or in the presence of equivocal findings, follow-up examinations in 3-6 months are strongly recommended.

\section{Definition of myeloma bone disease}

Bone disease in multiple myeloma, to meet the CRAB criteria, has been defined as the presence of osteolytic bone lesions or the presence of osteoporosis with compression fractures attributable to the underlying clonal plasma cell disorder. ${ }^{10,11}$ Traditionally, bone disease has been identified on the basis of conventional skeletal radiography. The 2003 IMWG criteria for the diagnosis of multiple myeloma concluded that MRI and CT can be used to clarify the presence of bone disease. ${ }^{10}$ Although the criteria did not explicitly state that these modalities can be used in isolation to fulfil the CRAB criteria in the absence of bone disease on skeletal radiography, it was the intent of the investigators that a definite osteolytic lesion detected on CT should be regarded as fulfilling CRAB criteria even if it was not visible on conventional skeletal radiography (RAK, unpublished data). In the past 10 years substantial advances have been made in imaging technology, as well as more widespread use of MRI, low-dose whole-body CT, and FDG-PET to assess bone disease and bone marrow infiltration in multiple myeloma. ${ }^{54,55,77-81}$ A 2013 systematic review ${ }^{56}$ compared $^{2}$ modern imaging methods including MRI, FDG-PET, PET-CT, and whole-body CT with conventional wholebody skeletal radiography. Newer imaging techniques had greater sensitivity than radiographic bone survey for detection of multiple myeloma bone lesions, with as many as $80 \%$ or more lesions detected by the newer imaging techniques. CT and MRI were equally sensitive, and thus either test can be used, depending on availability and access. Furthermore, the IMWG recommended the use of these techniques during the diagnostic assessment of patients with smouldering multiple myeloma and solitary plasmacytoma. ${ }^{21}$ The IMWG recommends that one of PET-CT, low-dose whole-body CT, or MRI of the whole-body or spine be done in all patients with suspected smouldering multiple myeloma, with the exact imaging modality determined by availability and resources.

In this updated IMWG criteria, we now clarify that clear evidence of one or more sites of osteolytic bone destruction ( $\geq 5 \mathrm{~mm}$ in size) seen on CT (including lowdose whole-body CT) or PET-CT does fulfil the criteria for 
bone disease in multiple myeloma, and should be regarded as meeting the $\mathrm{CRAB}$ requirement irrespective of whether they can be visualised on skeletal radiography or not. Increased uptake on PET-CT alone is not adequate for the diagnosis of multiple myeloma; evidence of underlying osteolytic bone destruction is needed on the CT portion of the examination. Among 13 patients at the Mayo Clinic with suspected smouldering multiple myeloma and one or more osteolytic lesions on PET-CT who were observed without therapy, ten progressed within 2 years (SVR, unpublished data). Care should be taken to avoid over-interpretation of equivocal or tiny lucencies seen only on CT or PET-CT; as with skeletal surveys, if there are doubts about the nature of these lesions, a repeat study in 3-6 months should be done before a diagnosis of multiple myeloma is made. Such patients might be followed up closely at 1-3 month intervals before systemic therapy is started. Similarly, patients could have other concurrent malignancies with associated bone metastases. When the diagnosis is in doubt, a biopsy of one of the bone lesions should be considered. Furthermore, in view of the incorporation and availability of more sensitive imaging modalities to identify osteolytic bone destruction, we no longer recommend the presence of osteoporosis or vertebral compression fractures alone in the absence of lytic lesions as being sufficient evidence of bone disease for purposes of the diagnostic criteria. However, if vertebral compression fractures are seen in younger patients with monoclonal gammopathy, judgment should be exercised, and additional imaging such as CT or PET-CT should be done to clarify that the changes are not related to myeloma. Bone densitometry studies are not sufficient to determine presence of multiple myeloma bone disease. Overdiagnosis of multiple myeloma among elderly patients with MGUS would be highly likely if osteoporosis and compression fractures alone were regarded as sufficient for CRAB features.

When only one osteolytic bone lesion is seen in the presence of $10 \%$ or more clonal plasma cells, no clear indication is present for systemic therapy if no other criteria are met for active myeloma, and further thought is needed. This circumstance is rare, and we recommend that patients could be given radiation therapy and observed. Clinical trials to determine the value of adjuvant systemic therapy for these patients are being planned.

\section{Definition of renal failure}

Renal insufficiency is defined in the 2003 IMWG criteria as a serum creatinine concentration of more than $173 \mu \mathrm{mol} / \mathrm{L}$ (roughly $>2 \mathrm{mg} / \mathrm{dL}$ ) that is attributable to multiple myeloma; this value corresponds to an increase of $40 \%$ above the normal upper limit of the serum creatinine. ${ }^{10}$ However, use of a fixed concentration of serum creatinine to define renal insufficiency results in patients needing widely different levels of renal dysfunction, based on age, sex, and race, to fulfil the diagnostic criteria for multiple myeloma. For example, a serum creatinine concentration of $173 \mu \mathrm{mol} / \mathrm{L}$ in an individual weighing $70 \mathrm{~kg}$ corresponds to glomerular filtration rates of $38 \mathrm{~mL} / \mathrm{min}$ in a 40 -year-old man, $28 \mathrm{~mL} / \mathrm{min}$ in a 40 -year-old woman, $35 \mathrm{~mL} / \mathrm{min}$ in a 65-year-old man, and $26 \mathrm{~mL} / \mathrm{min}$ in a 65-year-old woman. This drawback is well-recognised, and has already been addressed in most modern clinical trials, in which creatinine clearance (estimated glomerular filtration rates) is used for eligibility criteria. The IMWG therefore recommends that measured or estimated glomerular filtration rates (according to the modification of diet in renal disease [MDRD] or chronic kidney disease epidemiology collaboration [CKD-EPI] formulae) less than $40 \mathrm{~mL} / \mathrm{min}$ (which corresponds to about a $40 \%$ decrease from the lower limit of the normal glomerular filtration rates) be used instead of a fixed serum creatinine concentration to fulfil the CRAB criteria. This ensures that a similar level of renal dysfunction attributable to the underlying plasma cell disorder is used to define the disease.

The criteria have also been updated to clarify that only renal failure caused by light-chain cast nephropathy (based on typical histological changes or presumptive diagnosis based on the presence of high involved FLC levels, typically $>1500 \mathrm{mg} / \mathrm{L}$ ) is regarded as a myeloma-defining events. Although other forms of renal damage (eg, AL amyloidosis, monoclonal immunoglobulin deposition disease, lightchain Fanconi syndrome, monoclonal gammopathyassociated membranoproliferative glomerulonephritis) can occur in multiple myeloma, this association is not characteristic of multiple myeloma and can be seen with other types of plasma cell dyscrasias (eg, MGUS) or lymphoproliferative disorders. Although they can occur in conjunction with multiple myeloma, in most patients they occur independently without evidence of other myelomadefining events. For this reason, these renal disorders are not regarded as myeloma-defining events, and should not lead to multiple myeloma diagnosis, unless they meet criteria for multiple myeloma as listed in the panel. These entities represent unique disease states with clearly defined pathological features, diagnostic criteria, prognosis, and therapy. Some investigators have collectively referred to these disorders under the term monoclonal gammopathy of renal significance..$^{82}$ Other causes of acute and chronic renal failure (eg, diabetic nephropathy, nephrotoxic drugs, pre-renal failure) should be carefully excluded. We recommend a renal biopsy to clarify the underlying cause of the renal failure in patients with suspected cast nephropathy, especially if the serum involved FLC levels are less than $500 \mathrm{mg} / \mathrm{L}$, which is also consistent with the recommendations of the International Kidney and Monoclonal Gammopathy Research Group. ${ }^{83}$

\section{Monoclonal protein requirements}

The 2003 IMWG criteria recognised that serum or urinary monoclonal protein is not present in all patients with 
multiple myeloma, and that a distinct subset of patients with non-secretory multiple myeloma exist (representing about $3 \%$ of multiple myeloma) who have no detectable abnormalities on serum or urine immunofixation..$^{10}$ Roughly $30 \%$ of such patients also have a normal serum FLC assay. ${ }^{84}$ Because these patients clearly have multiple myeloma by virtue of meeting other required criteria, and since the clonal nature of the plasma cell proliferation is established on histopathology, the requirement for monoclonal protein presence as part of the diagnostic criteria is not mandatory. Instead, the presence or absence of an monoclonal protein is used to subdivide multiple myeloma into secretory and non-secretory types.

\section{Bone marrow plasma cell requirements}

A bone marrow examination showing presence of clonal plasma cells or histopathological evidence of a plasmacytoma is a definite requirement for the diagnosis of multiple myeloma. In the 2003 IMWG criteria,$^{10}$ the minimum percentage of BMPC needed for the diagnosis of multiple myeloma was not stated. Only 3-5\% of multiple myeloma is associated with BMPC of less than $10 \% .{ }^{85}$ The revised diagnostic criteria clarify that in these patients, the diagnosis of multiple myeloma needs a repeat bone marrow biopsy showing $10 \%$ or more clonal plasma cells, or an image-guided (CT or MRI) biopsy of a bony or extramedullary lesion (plasmacytoma). ${ }^{85}$ In some of these patients this trait is caused by sampling error or patchy bone marrow involvement, while in the others there are multiple plasmacytomas or lytic lesions with no generalised marrow involvement (macrofocal multiple myeloma).$^{86}$ CRAB features cannot be regarded as being attributable to clonal plasma cell proliferation if BMPC is less than $10 \%$ and there is no biopsy-proven plasmacytoma. Patients with related plasma cell proliferative disorders such as AL amyloidosis, POEMS syndrome, or monoclonal gammopathy-associated proliferative glomerulonephritis might seem to have CRAB-like features despite low levels of bone-marrow plasmacytosis. ${ }^{82,87,88}$ In these instances, the patient should not be defined as having concomitant multiple myeloma unless they meet the criteria listed in the panel. Based on these considerations, and to prevent patients with MGUS from being wrongly classified as multiple myeloma based on unrelated features of anaemia, hypercalcaemia, or renal dysfunction, the criteria have been updated to clarify that either clonal BMPC of $10 \%$ or more, or a biopsy-proven plasmacytoma, is needed for the diagnosis of multiple myeloma. Some patients who are suspected of having multiple myeloma with clonal BMPC of less than $10 \%$ might have lytic lesions or plasmacytomas that are inaccessible for biopsy; judgment should be used in the care of these patients, and additional bone marrow examinations or follow-up testing might be needed to clarify the diagnosis. Finally, patients with solitary plasmacytoma meeting criteria described in table 1 should not be regarded as having multiple myeloma.
The estimate of bone marrow plasmacytosis should be determined by conventional bone marrow aspirate or biopsy examination. If there is a discrepancy, the higher of the two values should be used. ${ }^{60}$ Clonality of bone marrow plasma cells should be established by demonstration of $\kappa / \lambda$ light-chain restriction by immunohistochemistry or immunofluorescence, or by demonstration of phenotypic clonality by flow cytometry, or by immunoglobulin gene rearrangement studies.

\section{Clarification of the need for symptoms}

CRAB features are typically associated with symptoms. However, we clarify that the term symptomatic is used to refer to patients with presence of CRAB features attributable to the underlying clonal plasma cell disorder, even if they are not symptomatic to the patient, but rather discovered during tests. This clarification is mainly to help in interpretation of existing trials. Since the updated criteria include other asymptomatic patient subgroups, this is of less importance now. The term multiple myeloma is preferred instead of the term symptomatic multiple myeloma.

\section{Other related organ or tissue impairment}

Although the 2003 IMWG criteria included non-CRAB end-organ damage, specifically hyperviscosity, AL amyloidosis, and recurrent bacterial infections as fulfilling criteria for multiple myeloma, over the years only CRAB features have been regarded as myelomadefining events. ${ }^{10,11}$ Hyperviscosity is seen mainly with high immunoglobulin A (IgA) levels (usually $>30 \mathrm{~g} / \mathrm{L}$ but varies between patients); such levels are almost never seen without other CRAB features, especially anaemia, as a substantial tumour load is needed to produce this event. Systemic AL amyloidosis is a distinct plasma cell dyscrasia, and its presence in a patient with a monoclonal gammopathy does not automatically suggest multiple myeloma. There are studies ${ }^{89}$ that try to define the specific myeloma-defining event needed for the diagnosis of concurrent multiple myeloma in patients with AL amyloidosis. Recurrent infection is a nonspecific criterion, and in view of the prevalence of MGUS in the elderly general population, it is not thought of as a validated or reliable myeloma-defining event in the absence of other CRAB features. Finally, all of these have also become less important with the inclusion of new non-CRAB biomarkers to define the disease. Thus, we do not recommend their use for the initiation of treatment.

Peripheral neuropathy is often seen in association with monoclonal gammopathies, and in some cases is causally related to the underlying monoclonal immunoglobulin. The pathogenesis is thought to be related to the effect of the monoclonal protein (or secondary biological mechanisms) on the peripheral nerves, and can occur in patients with MGUS without need for malignant transformation..$^{90}$ Thus, peripheral neuropathy alone is not a myeloma-defining event, and patients in whom a 


\begin{tabular}{|ll|}
\hline & 2-year probability of progression \\
\hline High levels of circulating plasma cells & $80 \%^{93}$ \\
\hline Abnormal plasma cell immunophenotype $\geq 95 \%$ plus immunoparesis & $50 \%^{28,3.949 .95}$ \\
\hline Evolution of smouldering multiple myeloma* & $65^{96}$ \\
\hline Cytogenetic subtypes: $t$ (4;14), 1q amp, or del 17p & $50 \%^{979.98}$ \\
High bone marrow plasma cell proliferative rate & $80 \%^{99}$ \\
\hline $\begin{array}{l}\text { Unexplained decrease in creatinine clearance by } \geq 25 \% \text { accompanied by a } \\
\text { rise in urinary monoclonal protein or serum free light-chain }\end{array}$ & Not known \\
concentrations & \\
*Increase in serum monoclonal protein by $\geq 10 \%$ on each of two successive evaluations within a 6-month period. \\
\hline Table 2: Potential future biomarkers for diagnosis of multiple myeloma \\
\hline
\end{tabular}

causal role of the monoclonal protein is suspected are regarded as having monoclonal gammopathy-associated neuropathy.

All CRAB features used for diagnosis must be attributable to the underlying plasma cell disorder. In particular, hypercalcaemia in the absence of clear multiple myeloma bone disease must be carefully investigated to rule out other causes such as hyperparathyroidism. Similarly, care should be taken in attribution of clinically significant anaemia as a CRAB criterion for multiple myeloma if the extent of BMPC involvement seems negligible relative to the degree of reduction in haemoglobin or haematocrit.

\section{Other specific disease states}

The present IMWG diagnostic criteria and recommended terminology for MGUS and related plasma cell disorders, including solitary plasmacytoma and immunoglobulin light-chain amyloidosis, are listed in table 1 . The prognosis of solitary plasmacytoma varies depending on presence of clonal plasma cells in the bone marrow. ${ }^{12-16}$ It therefore consists of two distinct entities: solitary plasmacytoma (no clonal BMPCs) and solitary plasmacytoma with low marrow involvement ( $<10 \%$ clonal BMPCs). By contrast, patients with solitary plasmacytoma and $10 \%$ or more of clonal plasma cells are classified as multiple myeloma. The IMWG also recommends that POEMS syndrome $^{91}$ and osteosclerotic multiple myeloma ${ }^{92}$ be regarded as distinct subtypes of multiple myeloma, given the markedly different clinical presentation, therapeutic approach, response to treatment, and prognosis.

\section{Future directions}

The updated diagnostic criteria move multiple myeloma into line with other malignancies by removing the need for documented end-organ damage as a mandatory requirement for the definition of malignancy. ${ }^{34,35,39-42,57}$ They address a major drawback in terminology that prevented patients with clearcut malignancy and very high risk of developing end-organ damage from receiving therapy until such damage is clinically manifest.

Promising markers for further study are listed in table 2. ${ }^{93-99}$ Multiparametric flow cytometry can help

\section{Search strategy and selection criteria}

We searched PubMed for articles published in English between Jan 1, 1980, and June 30, 2014, that contained the term "smoldering myeloma" and any one of the following terms: "prognosis" or "imaging" or "biomarkers" or "risk factors" or "progression" or "therapy". We also reviewed recent reviews on smouldering multiple myeloma. Members of the International Myeloma Working Group were then asked to identify any appropriate citation that was of interest but not detected by the search strategy.

distinguish clonal from normal plasma cells. In patients with MGUS, a substantial proportion of polyclonal plasma cells persist, whereas in multiple myeloma almost all plasma cells $(>95 \%)$ are clonal. ${ }^{28,94,95}$ Patients with smouldering multiple myeloma who display an immunophenotypic pattern identical to multiple myeloma have a higher risk of progression. ${ }^{38}$ High levels of circulating plasma cells and high proliferative rate of bone marrow plasma cells can accurately identify patients with ultra-high risk of progression, but the methods that have been reported are not universally available, and cut-off points using sensitive and automated multiparametric flow cytometric methods are needed..$^{93,99}$ Specific cytogenetic abnormalities, especially translocation $\mathrm{t}(4 ; 14)$, 1q gain, and deletion $17 \mathrm{p}$, have been associated with a high risk of progression in smouldering multiple myeloma and need to be combined with other known biomarkers to improve predictive value. ${ }^{97,98}$ In future, genomic markers will probably be incorporated to more accurately predict risk of progression..$^{100}$

An increase in the serum monoclonal protein level by at least $10 \%$ on two successive evaluations within a 6-month period has been associated with a 65\% probability of progression in smouldering multiple myeloma. ${ }^{96}$ However, in the observation group of the Spanish trial of smouldering multiple myeloma, ${ }^{38}$ patients with a rise in monoclonal protein of at least $25 \%$ over two successive evaluations did not have a significant increase in risk of progression compared with patients without such an increase (2-year risk of $69 \%$ with increased monoclonal protein vs $75 \%$ for controls; MMV, unpublished data). Even increasing the threshold to a $50 \%$ or $100 \%$ increase did not result in significant differences. However, the Spanish trial included only high-risk smouldering multiple myeloma, and more data are needed. ${ }^{96}$ At present, data are insufficient to incorporate increasing monoclonal protein as a myelomadefining event; we recommend that such patients be followed up more closely, and advanced imaging methods be considered to determine whether they meet the present diagnostic criteria for multiple myeloma.

Additional biomarkers with the same or better performance characteristics than the ones included in this updated definition will probably be identified with 
ongoing research. The IMWG recognises that validated (ie, substantiated by more than two independent studies) biomarkers associated with a risk of progression of smouldering multiple myeloma to multiple myeloma of at least $80 \%$ within 2 years can be added to the diagnostic criteria in the future.

\section{Contributors}

SVR and JSM wrote the first draft of the manuscript after reviewing scientific literature and discussion with members of the International Myeloma Working Group. All authors listed on the manuscript reviewed the draft, provided detailed input and comments, and contributed to the final report.

\section{Declaration of interests}

MAD reports personal fees from Celgene, Ortho Biotech, and Onyx. AP reports personal fees from Amgen, Bristol-Myers Squibb, Genmab A/S, Janssen-Cilag, Millennium Pharmaceuticals, Onyx Pharmaceuticals, Celgene, Sanofi Aventis, and Array BioPharma. JB reports personal fees from Celgene and Janssen. GM reports personal fees from Millennium Takeda. SK reports grants from Celgene, Millennium, Novartis, Cephalon/Teva, Abbvie, and Onyx. PR has been a member of advisory committees for Millennium, Celgene, Johnson \& Johnson, and Novartis. BP has received honoraria from Millennium, Celgene, Janssen, and The Binding Site Group Ltd. AD reports grants from Celgene, Millennium, Pfizer, and Jannsen. BW reports grants and personal fees from Janssen Research and Development, personal fees from Celgene and Onyx, and grants from Millennium. SZ reports grants from Celgene, Janssen, and Millennium. SL reports personal fees from Millennium, Celgene, Novartis, Onyx, Sanofi, Janssen, and Bristol-Myers Squibb. LR has received honoraria from Janssen and Celgene. EZ reports grants from Jansen-Cilag and Celgene. SJ has been a consultant for Celgene, Sanofi, and BristolMyers Squibb. OS reports personal fees from Celgene and Janssen. MB is in the speakers bureau for Celgene, Janssen-Cilag and Amgen, and serves on advisory boards for Janssen-Cilag, Bristol-Myers Squibb, and Novartis. MC reports personal fees from Janssen, Celgene, Millennium, Onyx, and Bristol-Myers Squibb. KCA reports personal fees from Celgene, Millennium, Gilead, Sanofi Aventis, and Onyx. All other authors declare no competing interests.

\section{References}

1 Palumbo A, Anderson K. Multiple myeloma. N Engl J Med 2011; 364: 1046-60.

2 Rajkumar SV. Treatment of multiple myeloma. Nat Rev Clin Oncol 2011; 8: 479-91.

3 Landgren O, Kyle RA, Pfeiffer RM, et al. Monoclonal gammopathy of undetermined significance (MGUS) consistently precedes multiple myeloma: a prospective study. Blood 2009; 113: 5412-17.

4 Weiss BM, Abadie J, Verma P, Howard RS, Kuehl WM. A monoclonal gammopathy precedes multiple myeloma in most patients. Blood 2009; 113: 5418-22.

5 Kyle RA, Therneau TM, Rajkumar SV, et al. Prevalence of monoclonal gammopathy of undetermined significance. N Engl J Med 2006; 354: 1362-69.

6 Landgren O, Graubard BI, Katzmann JA, et al. Racial disparities in the prevalence of monoclonal gammopathies: a population-based study of 12,482 persons from the National Health and Nutritional Examination Survey. Leukemia 2014; 28: 1537-42.

7 Bladé J. Monoclonal gammopathy of undetermined significance. N Engl J Med. 2006; 355: 2765-70

8 Dispenzieri A, Katzmann JA, Kyle RA, et al. Prevalence and risk of progression of light-chain monoclonal gammopathy of undetermined significance: a retrospective population-based cohort study. Lancet 2010; 375: 1721-28.

9 Merlini G, Palladini G. Differential diagnosis of monoclonal gammopathy of undetermined significance. Hematology (Am Soc Hematol Educ Program) 2012; 2012: 595-603.

10 International Myeloma Working Group. Criteria for the classification of monoclonal gammopathies, multiple myeloma and related disorders: a report of the International Myeloma Working Group. Br J Haematol 2003; 121: 749-57.
11 Kyle RA, Rajkumar SV. Criteria for diagnosis, staging, risk stratification and response assessment of multiple myeloma. Leukemia 2009; 23: 3-9.

12 Kyle RA, Larson DR, Therneau TM, et al. Clinical course of lightchain smouldering multiple myeloma (idiopathic Bence Jones proteinuria): a retrospective study. Lancet Haematol 2014; 1: e28-36.

13 Dimopoulos MA, Kiamouris C, Moulopoulos LA. Solitary plasmacytoma of bone and extramedullary plasmacytoma. Hematol Oncol Clin North Am 1999; 13: 1249-57.

14 Hill QA, Rawstron AC, de Tute RM, Owen RG. Outcome prediction in solitary plasmacytoma of bone: a risk stratification model utilizing bone marrow flow cytometry and light-chain analysis. Blood 2014; 124: 1296-99.

15 Paiva B, Chandia M, Vidriales MB, et al. Multiparameter flow cytometry for staging of solitary bone plasmacytoma: new criteria for risk of progression to myeloma. Blood 2014; 124: 1300-03.

16 Warsame R, Gertz MA, Lacy MQ, et al. Trends and outcomes of modern staging of solitary plasmacytoma of bone. Am J Hematol 2012; 87: 647-51.

17 Dispenzieri A, Kyle RA, Lacy MQ, et al. POEMS syndrome: definitions and long-term outcome. Blood 2003; 101: 2496-506.

18 Rajkumar SV, Dispenzieri A, Kyle RA. Monoclonal gammopathy of undetermined significance, Waldenström macroglobulinemia, AL amyloidosis, and related plasma cell disorders: diagnosis and treatment. Mayo Clin Proc 2006; 81: 693-703.

19 Dispenzieri A. POEMS syndrome. Blood Rev 2007; 21: 285-99.

20 Kyle RA, Therneau TM, Rajkumar SV, et al. Long-term follow-up of IgM monoclonal gammopathy of undetermined significance. Blood 2003; 102: 3759-64.

21 Kyle RA, Durie BGM, Rajkumar SV, et al, and the International Myeloma Working Group. Monoclonal gammopathy of undetermined significance (MGUS) and smoldering (asymptomatic) multiple myeloma: IMWG consensus perspectives risk factors for progression and guidelines for monitoring and management. Leukemia 2010; 24: 1121-27.

22 Landgren $\mathrm{O}$. Monoclonal gammopathy of undetermined significance and smoldering multiple myeloma: biological insights and early treatment strategies.

Hematology (Am Soc Hematol Educ Program) 2013; 2013: 478-87.

23 Schuster SR, Rajkumar SV, Dispenzieri A, et al. IgM multiple myeloma: disease definition, prognosis, and differentiation from Waldenstrom's macroglobulinemia. Am J Hematol 2010; 85: 853-55.

24 Turesson I, Kovalchik SA, Pfeiffer RM, et al. Monoclonal gammopathy of undetermined significance and risk of lymphoid and myeloid malignancies: 728 cases followed up to 30 years in Sweden. Blood 2014; 123: 338-45.

25 Kyle RA, Therneau TM, Rajkumar SV, et al. A long-term study of prognosis in monoclonal gammopathy of undetermined significance. N Engl J Med 2002; 346: 564-69.

26 Cesana C, Klersy C, Barbarano L, et al. Prognostic factors for malignant transformation in monoclonal gammopathy of undetermined significance and smoldering multiple myeloma. J Clin Oncol 2002; 20: 1625-34.

27 Rajkumar SV, Kyle RA, Therneau TM, et al. Serum free light chain ratio is an independent risk factor for progression in monoclonal gammopathy of undetermined significance. Blood 2005; 106: 812-17.

28 Pérez-Persona E, Vidriales MB, Mateo G, et al. New criteria to identify risk of progression in monoclonal gammopathy of uncertain significance and smoldering multiple myeloma based on multiparameter flow cytometry analysis of bone marrow plasma cells. Blood 2007; 110: 2586-92.

29 Katzmann JA, Clark R, Kyle RA, et al. Suppression of uninvolved immunoglobulins defined by heavy/light chain pair suppression is a risk factor for progression of MGUS. Leukemia 2013; 27: 208-12.

30 Kyle RA, Remstein ED, Therneau TM, et al. Clinical course and prognosis of smoldering (asymptomatic) multiple myeloma. $N$ Engl J Med 2007; 356: 2582-90.

31 Cherry BM, Korde N, Kwok M, et al. Modeling progression risk for smoldering multiple myeloma: results from a prospective clinical study. Leuk Lymphoma 2013; 54: 2215-18.

32 Kristinsson SY, Holmberg E, Blimark C. Treatment for high-risk smoldering myeloma. N Engl J Med 2013; 369: 1762-63. 
33 Rajkumar SV. Preventive strategies in monoclonal gammopathy of undetermined significance and smoldering multiple myeloma. Am J Hematol 2012; 87: 453-54.

34 Rajkumar SV, Merlini G, San Miguel JF. Haematological cancer: Redefining myeloma. Nat Rev Clin Oncol 2012; 9: 494-96.

35 Landgren O, Waxman AJ. Multiple myeloma precursor disease. JAMA 2010; 304: 2397-404.

36 Dimopoulos M, Kyle R, Fermand JP, et al, and the International Myeloma Workshop Consensus Panel 3. Consensus recommendations for standard investigative workup: report of the International Myeloma Workshop Consensus Panel 3. Blood 2011; 117: 4701-05

37 Rajkumar SV, Harousseau JL, Durie B, et al, and the International Myeloma Workshop Consensus Panel 1. Consensus recommendations for the uniform reporting of clinical trials: report of the International Myeloma Workshop Consensus Panel 1. Blood 2011; 117: 4691-95.

38 Mateos M-V, Hernández M-T, Giraldo P, et al. Lenalidomide plus dexamethasone for high-risk smoldering multiple myeloma. $N$ Engl J Med 2013; 369: 438-47.

39 Dispenzieri A, Stewart AK, Chanan-Khan A, et al. Smoldering multiple myeloma requiring treatment: time for a new definition? Blood 2013; 122: 4172-81.

40 Mailankody S, Mena E, Yuan CM, Balakumaran A, Kuehl WM, Landgren O. Molecular and biologic markers of progression in monoclonal gammopathy of undetermined significance to multiple myeloma. Leuk Lymphoma 2010; 51: 2159-70.

41 Landgren O, Rajkumar SV. Development of early treatment strategies for high-risk myeloma precursor disease in the future. Semin Hematol 2011; 48: 66-72.

42 Landgren O. Multiple myeloma precursor disease: current clinical dilemma and future opportunities. Semin Hematol 2011; 48: 1-3.

43 Rajkumar SV. Prevention of progression in monoclonal gammopathy of undetermined significance. Clin Cancer Res 2009; 15: 5606-08.

44 Dispenzieri A, Kyle RA, Katzmann JA, et al. Immunoglobulin free light chain ratio is an independent risk factor for progression of smoldering (asymptomatic) multiple myeloma. Blood 2008; 111: 785-89.

45 Rajkumar SV, Larson D, Kyle RA. Diagnosis of smoldering multiple myeloma. N Engl J Med 2011; 365: 474-75.

46 Richardson PG, Sonneveld P, Schuster MW, et al, and the Assessment of Proteasome Inhibition for Extending Remissions (APEX) Investigators. Bortezomib or high-dose dexamethasone for relapsed multiple myeloma. N Engl J Med 2005; 352: 2487-98.

47 Dimopoulos M, Spencer A, Attal M, et al, and the Multiple Myeloma (010) Study Investigators. Lenalidomide plus dexamethasone for relapsed or refractory multiple myeloma. N Engl J Med 2007; 357: 2123-32.

48 Rajkumar SV, Jacobus S, Callander NS, et al, and the Eastern Cooperative Oncology Group. Lenalidomide plus high-dose dexamethasone versus lenalidomide plus low-dose dexamethasone as initial therapy for newly diagnosed multiple myeloma: an openlabel randomised controlled trial. Lancet Oncol 2010; 11: 29-37.

49 Richardson PG, Weller E, Lonial S, et al. Lenalidomide, bortezomib, and dexamethasone combination therapy in patients with newly diagnosed multiple myeloma. Blood 2010; 116: 679-86.

50 Jakubowiak AJ, Dytfeld D, Griffith KA, et al. A phase 1/2 study of carfilzomib in combination with lenalidomide and low-dose dexamethasone as a frontline treatment for multiple myeloma. Blood 2012; 120: 1801-09.

51 Lacy MQ, Hayman SR, Gertz MA, et al. Pomalidomide (CC4047) plus low-dose dexamethasone as therapy for relapsed multiple myeloma. J Clin Oncol 2009; 27: 5008-14.

52 Hjorth M, Hellquist L, Holmberg E, Magnusson B, Rödjer S, Westin J, and the Myeloma Group of Western Sweden. Initial versus deferred melphalan-prednisone therapy for asymptomatic multiple myeloma stage I--a randomized study. Eur J Haematol 1993; 50: 95-102.

53 Riccardi A, Mora O, Tinelli C, et al, and the Cooperative Group of Study and Treatment of Multiple Myeloma. Long-term survival of stage I multiple myeloma given chemotherapy just after diagnosis or at progression of the disease: a multicentre randomized study. Br J Cancer 2000; 82: 1254-60.
54 Dimopoulos M, Terpos E, Comenzo RL, et al, and the IMWG International myeloma working group consensus statement and guidelines regarding the current role of imaging techniques in the diagnosis and monitoring of multiple Myeloma. Leukemia 2009; 23: $1545-56$.

55 Hillengass J, Landgren O. Challenges and opportunities of novel imaging techniques in monoclonal plasma cell disorders: imaging “early myeloma”. Leuk Lymphoma 2013; 54: 1355-63.

56 Regelink JC, Minnema MC, Terpos E, et al. Comparison of modern and conventional imaging techniques in establishing multiple myeloma-related bone disease: a systematic review. Br J Haematol 2013; 162: 50-61.

57 Kastritis E, Terpos E, Moulopoulos L, et al. Extensive bone marrow infiltration and abnormal free light chain ratio identifies patients with asymptomatic myeloma at high risk for progression to symptomatic disease. Leukemia 2013; 27: 947-53.

58 Waxman AJ, Mick R, Garfall AL, et al. Modeling the risk of progression in smoldering multiple myeloma. Proc Am Soc Clin Oncol 2014; 32: A8607 (abstr)

59 Johnsen HE, Bøgsted M, Klausen TW, et al, and the Nordic Myeloma Study (NMSG), and the Myeloma Stem Cell Network (MSCNET). Multiparametric flow cytometry profiling of neoplastic plasma cells in multiple myeloma. Cytometry B Clin Cytom 2010; 78: 338-47.

60 Rajkumar SV, Fonseca R, Dispenzieri A, et al. Methods for estimation of bone marrow plasma cell involvement in myeloma: predictive value for response and survival in patients undergoing autologous stem cell transplantation. Am J Hematol 2001; 68: 269-75.

61 Bradwell AR, Carr-Smith HD, Mead GP, et al. Highly sensitive, automated immunoassay for immunoglobulin free light chains in serum and urine. Clin Chem 2001; 47: 673-80.

62 Katzmann JA, Clark RJ, Abraham RS, et al. Serum reference intervals and diagnostic ranges for free kappa and free lambda immunoglobulin light chains: relative sensitivity for detection of monoclonal light chains. Clin Chem 2002; 48: 1437-44.

63 Bradwell AR, Carr-Smith HD, Mead GP, Harvey TC, Drayson MT. Serum test for assessment of patients with Bence Jones myeloma. Lancet 2003; 361: 489-91.

64 Dispenzieri A, Kyle R, Merlini G, et al, and the International Myeloma Working Group. International Myeloma Working Group guidelines for serum-free light chain analysis in multiple myeloma and related disorders. Leukemia 2009; 23: 215-24.

65 Kyrtsonis MC, Vassilakopoulos TP, Kafasi N, et al. Prognostic value of serum free light chain ratio at diagnosis in multiple myeloma. Br J Haematol 2007; 137: 240-43.

66 Snozek CLH, Katzmann JA, Kyle RA, et al. Prognostic value of the serum free light chain ratio in newly diagnosed myeloma: proposed incorporation into the international staging system. Leukemia 2008; 22: 1933-37.

67 Dingli D, Kyle RA, Rajkumar SV, et al. Immunoglobulin free light chains and solitary plasmacytoma of bone. Blood 2006; 108: 1979-83.

68 Larsen JT, Kumar SK, Dispenzieri A, Kyle RA, Katzmann JA, Rajkumar SV. Serum free light chain ratio as a biomarker for highrisk smoldering multiple myeloma. Leukemia 2013; 27: 941-46.

69 Moulopoulos LA, Dimopoulos MA, Smith TL, et al. Prognostic significance of magnetic resonance imaging in patients with asymptomatic multiple myeloma. J Clin Oncol 1995; 13: 251-56.

70 Mariette X, Zagdanski AM, Guermazi A, et al. Prognostic value of vertebral lesions detected by magnetic resonance imaging in patients with stage I multiple myeloma. Br J Haematol 1999; 104: 723-29.

71 Wang M, Alexanian R, Delasalle K, Weber D. Abnormal MRI of spine is the dominant risk factor for early progression of asymptomatic multiple myeloma. Blood 2003; 102: 687a.

72 Hillengass J, Fechtner K, Weber MA, et al. Prognostic significance of focal lesions in whole-body magnetic resonance imaging in patients with asymptomatic multiple myeloma. J Clin Oncol 2010; 28: $1606-10$.

73 Kastritis E, Moulopoulos LA, Terpos E, Koutoulidis V, Dimopoulos MA. The prognostic importance of the presence of more than one focal lesion in spine MRI of patients with asymptomatic (smoldering) multiple myeloma. Leukemia 2014; published online July 31. DOI:10.1038/leu.2014.230. 
74 Dimopoulos MA, Moulopoulos A, Smith T, Delasalle KB, Alexanian R. Risk of disease progression in asymptomatic multiple myeloma. Am J Med 1993; 94: 57-61.

75 Weber DM, Dimopoulos MA, Moulopoulos LA, Delasalle KB, Smith T, Alexanian R. Prognostic features of asymptomatic multiple myeloma. Br J Haematol 1997; 97: 810-14.

76 Merz M, Hielscher T, Wagner B, et al. Predictive value of longitudinal whole-body magnetic resonance imaging in patients with smoldering multiple myeloma. Leukemia 2014; 28: 1902-08.

77 Zamagni E, Cavo M. The role of imaging techniques in the management of multiple myeloma. Br J Haematol 2012 159: 499-513.

78 Zamagni E, Nanni C, Patriarca F, et al. A prospective comparison of $18 \mathrm{~F}$-fluorodeoxyglucose positron emission tomography-computed tomography, magnetic resonance imaging and whole-body planar radiographs in the assessment of bone disease in newly diagnosed multiple myeloma. Haematologica 2007; 92: 50-55.

79 Walker R, Barlogie B, Haessler J, et al. Magnetic resonance imaging in multiple myeloma: diagnostic and clinical implications. J Clin Oncol 2007; 25: 1121-28.

80 Bartel TB, Haessler J, Brown TL, et al. F18-fluorodeoxyglucose positron emission tomography in the context of other imaging techniques and prognostic factors in multiple myeloma. Blood 2009; 114: 2068-76.

81 Waheed S, Mitchell A, Usmani S, et al. Standard and novel imaging methods for multiple myeloma: correlates with prognostic laboratory variables including gene expression profiling data. Haematologica 2013; 98: 71-78.

82 Leung N, Bridoux F, Hutchison CA, et al, and the International Kidney and Monoclonal Gammopathy Research Group. Monoclonal gammopathy of renal significance: when MGUS is no longer undetermined or insignificant. Blood 2012; 120: 4292-95.

83 Hutchison CA, Batuman V, Behrens J, et al, and the International Kidney and Monoclonal Gammopathy Research Group. The pathogenesis and diagnosis of acute kidney injury in multiple myeloma. Nat Rev Nephrol 2012; 8: 43-51.

84 Katzmann JA, Abraham RS, Dispenzieri A, Lust JA, Kyle RA Diagnostic performance of quantitative kappa and lambda free light chain assays in clinical practice. Clin Chem 2005; 51: 878-81.

85 Kyle RA, Gertz MA, Witzig TE, et al. Review of 1027 patients with newly diagnosed multiple myeloma. Mayo Clin Proc 2003; 78: 21-33.

86 Dimopoulos MA, Pouli A, Anagnostopoulos A, et al. Macrofocal multiple myeloma in young patients: a distinct entity with favorable prognosis. Leuk Lymphoma 2006; 47: 1553-56.
87 Dispenzieri A. How I treat POEMS syndrome. Blood 2012; 119: $5650-58$.

88 Sethi S, Rajkumar SV. Monoclonal gammopathy-associated proliferative glomerulonephritis. Mayo Clin Proc 2013; 88: 1284-93.

89 Kourelis TV, Kumar SK, Gertz MA, et al. Coexistent multiple myeloma or increased bone marrow plasma cells define equally high-risk populations in patients with immunoglobulin light chain amyloidosis. J Clin Oncol 2013; 31: 4319-24.

90 Nobile-Orazio E. Neuropathy and monoclonal gammopathy. Handb Clin Neurol 2013; 115: 443-59.

91 Dispenzieri A. POEMS syndrome: 2014 update on diagnosis, risk stratification, and management. Am J Hematol 2014; 89: 214-23.

92 Lacy MQ, Gertz MA, Hanson CA, Inwards DJ, Kyle RA. Multiple myeloma associated with diffuse osteosclerotic bone lesions: a clinical entity distinct from osteosclerotic myeloma (POEMS syndrome). Am J Hematol 1997; 56: 288-93.

93 Bianchi G, Kyle RA, Larson DR, et al. High levels of peripheral blood circulating plasma cells as a specific risk factor for progression of smoldering multiple myeloma. Leukemia 2013; 27: 680-85.

94 Pérez-Persona E, Mateo G, García-Sanz R, et al. Risk of progression in smouldering myeloma and monoclonal gammopathies of unknown significance: comparative analysis of the evolution of monoclonal component and multiparameter flow cytometry of bone marrow plasma cells. Br J Haematol 2010; 148: 110-14.

95 Rawstron AC, Orfao A, Beksac M, et al, and the European Myeloma Network. Report of the European Myeloma Network on multiparametric flow cytometry in multiple myeloma and related disorders. Haematologica 2008; 93: 431-38.

96 Rosiñol L, Bladé J, Esteve J, et al. Smoldering multiple myeloma: natural history and recognition of an evolving type. $\mathrm{Br} J$ Haematol 2003; 123: 631-36.

97 Rajkumar SV, Gupta V, Fonseca R, et al. Impact of primary molecular cytogenetic abnormalities and risk of progression in smoldering multiple myeloma. Leukemia 2013; 27: 1738-44.

98 Neben K, Jauch A, Hielscher T, et al. Progression in smoldering myeloma is independently determined by the chromosoma abnormalities del(17p), t(4;14), gain 1q, hyperdiploidy, and tumor load. J Clin Oncol 2013; 31: 4325-32.

99 Madan S, Kyle RA, Greipp PR. Plasma cell labeling index in the evaluation of smoldering (asymptomatic) multiple myeloma. Mayo Clin Proc 2010; 85: 300.

100 Dhodapkar MV, Sexton R, Waheed S, et al. Clinical, genomic, and imaging predictors of myeloma progression from asymptomatic monoclonal gammopathies (SWOG S0120). Blood 2014; 123: 78-85. 